\title{
Statin use and risk of nonmelanoma skin cancer: a nationwide study in Denmark
}

\author{
S Arnspang ${ }^{1}$, A Pottegård ${ }^{1,2}$, S Friis ${ }^{3,4,5}$, O Clemmensen ${ }^{6}, \mathrm{~K}$ E Andersen ${ }^{7}$, J Hallas ${ }^{1,2}$ and D Gaist ${ }^{*, 8}$ \\ ${ }^{1}$ Clinical Pharmacology, Institute of Public Health, University of Southern Denmark, J.B. Winsløws Vej 19, 2.sal, 5000 Odense C, \\ Denmark; ${ }^{2}$ Department of Clinical Chemistry \& Pharmacology, Odense University Hospital, J.B. Winsløws Vej 19, 2.sal, 5000 \\ Odense C, Denmark; ${ }^{3}$ Danish Cancer Society Research Centre, Strandboulevarden 49, 2100, Copenhagen $\varnothing$, Denmark; ${ }^{4}$ Faculty of \\ Health, Institute of Clinical Medicine, Aarhus University, Aarhus, Denmark; ${ }^{5}$ Department of Public Health, University of \\ Copenhagen, Copenhagen, Denmark; ${ }^{6}$ Department of Clinical Pathology, Odense University Hospital, J.B. Winsløws Vej 15, 5000 \\ Odense C, Denmark; ${ }^{7}$ Department of Dermatology and Allergy Centre, Odense University Hospital, Institute of Clinical Research, \\ Faculty of Health Sciences, University of Southern Denmark, Sdr. Boulevard 29, 5000 Odense C, Denmark and ${ }^{8}$ Department of \\ Neurology, Odense University Hospital, Institute of Clinical Research, Faculty of Health Sciences, University of Southern Denmark, \\ Sdr. Boulevard 29, 5000 Odense C, Denmark
}

Background: Evidence is conflicting regarding statin use and risk of basal cell (BCC) and squamous cell skin cancer (SCC).

Methods: Using Danish nationwide registries, we identified all patients with incident BCC/SCC during 2005-2009 and matched them to population controls. We computed odds ratios (ORs) for BCC and SCC associated with statin use.

Results: We identified 38484 cases of BCC and 3724 cases of SCC. Statin ever use was associated with ORs of 1.09 (Cl: 1.06-1.13) for BCC and 1.01 (Cl: 0.91-1.11) for SCC.

Conclusions: Statin use was not associated with risk of SCC. Residual confounding plausibly explains the marginally increased risk of BCC.

Nonmelanoma skin cancer (NMSC), the most common human cancer, occurs predominantly in elderly individuals. NMSCs include two main histological types, that is, basal cell carcinoma (BCC) and squamous cell carcinoma (SCC) (Madan et al, 2010). Age-adjusted incidence rates of both BCC and SCC have been increasing during recent decades (Madan et al, 2010). Some laboratory studies have demonstrated antineoplastic effect of statins against NMSC (Dimitroulakos et al, 2006; Zhao et al, 2010). However, the results of both laboratory and human studies are equivocal and two meta-analyses of statin use and risk of NMSC have given conflicting results. Kuoppala et al (2008) reported an increased risk for NMSC, whereas Li et al (2014) found a neutral effect. The conflicting evidence on statin use and NMSC risk prompted us to conduct a large nationwide study of statin use and risk of BCC or SCC.

\section{MATERIALS AND METHODS}

Our study was designed as a nested case-control study, based on information from nationwide Danish registries. The registries were linked by means of the civil registration number assigned to all Danish residents (Pedersen, 2011). Danish citizens, who are mainly Caucasians, have equal tax-supported access to health care provided by the Danish National Health Service.

From the Danish Cancer Registry (DCR) (Gjerstorff, 2011) we identified all individuals with a histologically verified first diagnosis of BCC or SCC between 1 January 2005 and 31 December 2009 and no prior cancer diagnosis. The date of diagnosis recorded in the DCR was defined as the index date.

For each case we randomly selected 10 age- and sex-matched population controls using risk-set sampling (Rothman et al, 2008; Pedersen, 2011). We restricted the subjects to persons who had

*Correspondence: Professor D Gaist; E-mail: dgaist@health.sdu.dk

Revised 20 August 2014; accepted 9 September 2014; published online 7 October 2014

(c) 2015 Cancer Research UK. All rights reserved 0007-0920/15 
resided in Denmark for at least 10 consecutive years before the index date and excluded organ recipients.

We retrieved prescription data from 1995 (where nationwide recording of prescription use was initiated in the Prescription Registry) to 1 year before the index date for both cases and controls. Statin use was classified as ever use ( $\geqslant 2$ statin prescriptions; ATC group $\mathrm{C} 10 \mathrm{AA})$ or nonuse (0 or 1 statin prescription). We furthermore calculated the cumulative duration, cumulative amount, and intensity of statin use and classified statins by lipophilicity.

We used conditional logistic regression to compute crude and adjusted odds ratios (ORs) and 95\% confidence intervals (CIs) for BCC or SCC associated with statin use. In all analyses, statin use was compared with nonuse. In the regression models, we included use of systemic glucocorticoids, azathioprine, other immunosuppressants, thiazides, other diuretics, hormone replacement therapy, amiodarone, low-dose aspirin, and nonaspirin nonsteroidal antiinflammatory (NSAID) drugs. From the Danish patient register, we obtained information on history of chronic obstructive pulmonary disease (COPD) (as a proxy measure for heavy tobacco smoking), connective tissue disease, moderate to severe kidney disease, diabetes, psoriasis, and atopic dermatitis in the models. We classified subjects according to the Charlson comorbidity index (CCI) score (Charlson et al, 1987), and as a marker of socioeconomic status we included information on the highest educational level achieved by study subjects.

The online supplement provides further description of the utilised registries, definition of drug exposure and covariates, and supplementary analyses.

\section{RESULTS}

The study population is depicted in Figure 1. Compared with controls, cases of BCC had more years of schooling, lower prevalence of diabetes and COPD, lower CCI scores, and higher user prevalence of azathioprine, glucocorticoid, other immunosuppressants, and thiazides (Supplementary Table 1). Squamous cell carcinoma cases had a higher prevalence of diabetes, psoriasis, atopic dermatitis, COPD, connective tissue disease, and kidney disease than their corresponding controls. A higher comorbidity among SCC cases was also reflected by higher CCI scores and higher use of most of the selected drugs (Supplementary Table 1).

Overall, $17.5 \%$ of BCC cases and $20.9 \%$ of SCC cases were ever users of statins compared with 17.2 and $19.4 \%$ among controls (Supplementary Table 1). This yielded adjusted ORs of 1.09 (95\% CI: $1.06-1.13)$ and $1.01(0.91-1.11)$, respectively, for the association between ever statin use and risk of BCC or SCC (Table 1). Analyses by duration of statin use and cumulative use yielded similar results as did restriction to study subjects with index dates during 2008-2009 with $10+$ years of statin exposure.

We observed lower ORs for use of hydrophilic statins than for use of lipophilic statins, notably for SCC (lipophilic: OR 1.08, 95\% CI: 0.89-1.30; hydrophilic OR 0.78, 95\% CI: 0.40-1.51) (Table 1). Analyses by specific statin drugs yielded ORs around unity for the most frequently used statins, whereas elevated ORs were observed for less frequently used statins, for example, fluvastatin (BCC: OR, 1.59; 95\% CI: 1.17-2.16). However, the OR estimates for the individual statins were based on small numbers.

Statin use was associated with slightly higher ORs for BCC and SCC in women compared with men (Supplementary Table 2). In addition, study subjects $>75$ years had slightly elevated ORs for both BCC and SCC with long-term use ( $\geqslant 5$ years) of statins (Supplementary Table 2). Stratification by age and gender, respectively, yielded some variation in ORs but no clear patterns. The remaining supplementary analyses yielded results for BCC and SCC similar to those of the main analyses (data not shown).

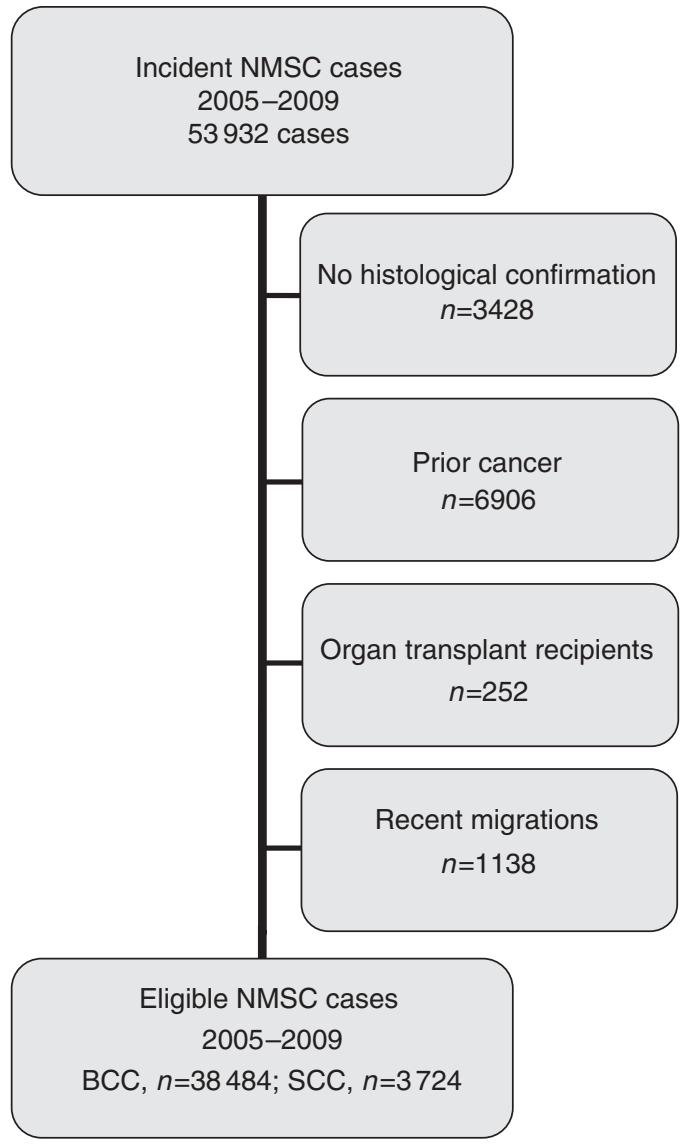

Figure 1. Flow-chart of inclusion of cases of nonmelanoma skin cancer in Denmark 2005-2009.

\section{DISCUSSION}

In this large population-based study, we found no apparent association between long-term use of statins and risk of BCC or SCC. Furthermore, risk estimates for BCC or SCC did not differ materially according to duration, cumulated dose, or type of statin.

Few previous epidemiological studies have addressed the risk of NMSC associated with statin use. In a post-trial analysis of the Veterans Affairs Topical Tretinoin Chemoprevention trial (Dore et al, 2009), no association was found in a propensity scorematched analyses of the study cohort (BCC: RR, 0.92; 95\% CI: $0.73-$ 1.16, SCC: RR, 0.88; 95\% CI: 0.63-1.23). Another US study (Asgari et al, 2009) reported a neutral RR of 1.01 (95\% CI: 0.92-1.12) for secondary BCC among patients with primary BCC, whereas longterm ( $>5$ years) statin use was associated with a slightly increased RR of 1.29 (95\% CI: 0.93-1.81). In a large record-linkage study from Finland, long-term ( $>5$ years) statin use was associated with an increased risk of NMSC (RR, 1.33; 95\% CI: 1.15-1.54), although tests for trend were significant only for pravastatin (Haukka et al, 2010). No disease-specific estimates were reported for BCC or SCC. Finally, two meta-analyses reported cumulative results on the risk of NMSC associated with statin use (Kuoppala et al, 2008, Li et al, 2014). In the study by Kuoppala et al (2008) that included data only from RCTs of statin, the authors reported a $30-60 \%$ (depending on study selection) increased risk of NMSC among statin users. In a more recent meta-analysis, including data from both RCTs and observational studies, no apparent association was found between statin use and NMSC risk (Li et al, 2014). Thus, although methodological issues hamper straightforward comparisons, our finding of no apparent link between use of statin and risk of NMSC is in line with most previous studies. 
Table 1. Association between exposure to statins and nonmelanoma skin cancer

\begin{tabular}{|c|c|c|c|c|}
\hline \multirow[b]{2}{*}{ Statin use } & \multicolumn{2}{|c|}{ Basal cell carcinoma } & \multicolumn{2}{|c|}{ Squamous cell carcinoma } \\
\hline & Cases $(n=38484)$ & Adj OR ${ }^{a}(95 \% \mathrm{Cl})$ & Cases $(n=3724)$ & Adj OR ${ }^{a}(95 \% \mathrm{Cl})$ \\
\hline $\begin{array}{l}\text { Nonuse } \\
\text { Ever use }\end{array}$ & $\begin{array}{r}31740 \\
6152\end{array}$ & $\begin{array}{l}1.00 \text { (ref) } \\
1.09(1.06-1.13)\end{array}$ & $\begin{array}{r}2946 \\
713\end{array}$ & $\begin{array}{l}1.00 \text { (ref) } \\
1.01(0.91-1.11)\end{array}$ \\
\hline \multicolumn{5}{|c|}{ Duration of use, years } \\
\hline $\begin{array}{l}<1 \\
\geqslant 1,<3 \\
\geqslant 3,<5 \\
\geqslant 5\end{array}$ & $\begin{array}{l}1863 \\
2148 \\
1315 \\
1418\end{array}$ & $\begin{array}{l}1.07(1.02-1.13) \\
1.06(1.01-1.12) \\
1.13(1.06-1.20) \\
1.11(1.03-1.17)\end{array}$ & $\begin{array}{l}177 \\
268 \\
162 \\
171\end{array}$ & $\begin{array}{l}0.91(0.77-1.08) \\
1.08(0.93-1.25) \\
1.07(0.89-1.29) \\
1.02(0.85-1.22)\end{array}$ \\
\hline \multicolumn{5}{|c|}{ Cumulative amount, DDD } \\
\hline $\begin{array}{l}<200 \\
200-499 \\
500-999 \\
1000-1999 \\
\geqslant 2000\end{array}$ & $\begin{array}{r}1276 \\
1352 \\
1641 \\
1634 \\
841\end{array}$ & $\begin{array}{l}1.11(1.04-1.18) \\
1.06(1.00-1.13) \\
1.09(1.03-1.16) \\
1.09(1.03-1.16) \\
1.07(0.99-1.16)\end{array}$ & $\begin{array}{l}116 \\
149 \\
209 \\
191 \\
113\end{array}$ & $\begin{array}{l}0.91(0.75-1.12) \\
1.00(0.83-1.20) \\
1.11(0.95-1.31) \\
0.99(0.84-1.18) \\
1.06(0.85-1.32)\end{array}$ \\
\hline \multicolumn{5}{|c|}{ Type of statin } \\
\hline $\begin{array}{l}\text { Lipophilic } \\
\text { Hydrophilic }\end{array}$ & $\begin{array}{r}1242 \\
82\end{array}$ & $\begin{array}{l}1.11(1.04-1.18) \\
0.95(0.75-1.20)\end{array}$ & $\begin{array}{r}153 \\
10\end{array}$ & $\begin{array}{l}1.08(0.89-1.30) \\
0.78(0.40-1.51)\end{array}$ \\
\hline \multicolumn{5}{|c|}{ Intensity of treatment, DDD/year } \\
\hline $\begin{array}{l}0-199 \\
200-399 \\
400+\end{array}$ & $\begin{array}{l}395 \\
721 \\
302\end{array}$ & $\begin{array}{l}1.18(1.04-1.32) \\
1.09(1.00-1.18) \\
1.04(0.92-1.18)\end{array}$ & $\begin{array}{l}49 \\
78 \\
44\end{array}$ & $\begin{array}{l}1.09(0.80-1.49) \\
0.96(0.74-1.23) \\
1.08(0.77-1.51)\end{array}$ \\
\hline \multicolumn{5}{|c|}{ Statin drug ${ }^{b}$} \\
\hline $\begin{array}{l}\text { Simvastatin } \\
\text { Lovastatin } \\
\text { Pravastatin } \\
\text { Fluvastatin } \\
\text { Atorvastatin }\end{array}$ & $\begin{array}{r}706 \\
49 \\
76 \\
51 \\
206\end{array}$ & $\begin{array}{l}1.10(1.01-1.19) \\
1.03(0.76-1.38) \\
0.93(0.73-1.19) \\
1.59(1.17-2.16) \\
1.03(0.89-1.20)\end{array}$ & $\begin{array}{r}91 \\
8 \\
10 \\
3 \\
22\end{array}$ & $\begin{array}{l}1.05(0.83-1.33) \\
1.33(0.62-2.84) \\
0.80(0.41-1.56) \\
0.59(0.18-1.34) \\
0.85(0.54-1.34)\end{array}$ \\
\hline \multicolumn{5}{|c|}{$\begin{array}{l}\text { Abbreviations: } 95 \% \mathrm{Cl}=95 \% \text { confidence interval; } \mathrm{OR}=\text { odds ratio. } \\
\text { a Adjusted for age, gender, years of schooling, history of atopic dermatitis, psoriasis, COPD, diabetes, CCl-score, and use of systemic glucocorticoids, azathioprine, other immunosuppressants, } \\
\text { thiazides, other diuretics, hormone replacement therapy, amiodarone, low-dose aspirin, or non-aspirin NSAID drugs } \\
\text { b }_{\text {Use for } \geqslant 5 \text { years versus nonuse; cerivastatin and rosuvastatin not presented owing to small numbers. }}\end{array}$} \\
\hline
\end{tabular}

Our study had a number of strengths. We used a nationwide prescription registry to assess statin use, an approach that provided detailed long-term drug use histories and eliminated recall bias. In Denmark, statins can only be obtained by prescription. Our use of nationwide registries with virtually complete coverage and continuously updated data on demographic characteristics, hospital contacts and cancer outcomes minimised selection bias. During the study period, the registration of NMSC in the DCR was based on reports from the primary health care sector and the patient register combined with diagnoses from the pathology registry, which holds records of all histological examinations of skin biopsies performed by private practitioners and at hospitals. This secured complete ascertainment of histologically verified NMSC cases and allowed evaluation of the association with statin use by histological type of NMSC.

Our study also had some potential limitations. First, we were not able to adjust for differences in sun habits. A high cumulated level of sunlight exposure is associated with an average 3.5-fold excess risk of SSC (English et al, 1998). This level of sunlight exposure has been estimated to pertain to $\sim 25 \%$ of a Western population (English et al, 1998). Using these figures combined with the exposure prevalence of $16 \%$ for statins in our study and the 'rule-out' approach (Schneeweiss, 2006), we estimated that even a statin-sunlight exposure association as low as 1.38 would fully explain an observed OR of 1.1 for statins and SCC. The slight increase in risk of NMSC associated with statin use observed in our study can therefore easily be explained by residual confounding by sunlight exposure or other unmeasured confounding. According to a recent Danish survey of 13996 individuals, statin users had less healthy lifestyle profiles than nonusers of the drug; however, that study did not include data on sun light exposure (Thomsen et al, 2013). Second, we cannot exclude some degree of socioeconomic confounding, although the study was conducted in a population with tax-supported free access to health care and, further, adjustment was performed for education in the analyses. A previous Danish survey reported a clear socioeconomic gradient in statin use among men but not women (Thomsen et al, 2005); however, the gradient was markedly lower in the recent survey (Thomsen et al, 2013).

In conclusion, our study does not indicate a major association between statin use and risk of BCC or SCC.

\section{ACKNOWLEDGEMENTS}

This study was supported by a grant from the Danish Cancer Society (Grant nr. R72-A4417). The funding source had no role in the design of the study, data analysis or interpretation of the results.

\section{REFERENCES}

Asgari MM, Tang J, Epstein EH Jr, Chren MM, Warton EM, Quesenberry CP Jr, Go AS, Friedman GD (2009) Statin use and risk of basal cell carcinoma. J Am Acad Dermatol 61: 66-72.

Charlson ME, Pompei P, Ales KL, MacKenzie CR (1987) A new method of classifying prognostic comorbidity in longitudinal studies: development and validation. J Chronic Dis 40: 373-383.

Dimitroulakos J, Lorimer IA, Goss G (2006) Strategies to enhance epidermal growth factor inhibition: Targeting the mevalonate pathway. Clin Cancer Res 12: 4426s-4431s.

Dore DD, Lapane KL, Trivedi AN, Mor V, Weinstock MA (2009) Association between statin use and risk for keratinocyte carcinoma in the veterans affairs topical tretinoin chemoprevention trial. Ann Intern Med 150: 9-18. 
English DR, Armstrong BK, Kricker A, Winter MG, Heenan PJ, Randell PL (1998) Case-control study of sun exposure and squamous cell carcinoma of the skin. Int J Cancer 77: 347-353.

Gjerstorff ML (2011) The Danish Cancer Registry. Scand J Public Health 39(Suppl 7): 42-45.

Haukka J, Sankila R, Klaukka T, Lonnqvist J, Niskanen L, Tanskanen A, Wahlbeck K, Tiihonen J (2010) Incidence of cancer and statin usagerecord linkage study. Int J Cancer 126: 279-284.

Kuoppala J, Lamminpää A, Pukkala E (2008) Statins and cancer: a systematic review and meta-analysis. Eur J Cancer 44: 2122-2232.

Li X, Wu XB, Chen Q (2014) Statin use is not associated with reduced risk of skin cancer: a meta-analysis. $\mathrm{Br} J$ Cancer 110: 802-807.

Madan V, Lear JT, Szeimies R-M (2010) Non-melanoma skin cancer. Lancet 375: 673-685.

Pedersen CB (2011) The Danish civil registration system. Scand J Public Health 39(7 Suppl): 22-25.
Rothman K, Greenland S, Lash TL (2008) Modern Epidemiology 3rd Edn. Wolters Kluwer Health. Lippincott Williams \& Wilkins: Philadelphia.

Schneeweiss S (2006) Sensitivity analysis and external adjustment for unmeasured confounders in epidemiologic database studies of therapeutics. Pharmacoepidemiol Drug Safety 15: 291-303.

Thomsen RW, Johnsen SP, Olesen AV, Mortensen JT, Bøggild H, Olsen J, Sørensen HT (2005) Socioeconomic gradient in use of statins among Danish patients: population-based cross-sectional study. $\mathrm{Br} J \mathrm{Clin}$ Pharmacol 60: 534-542.

Thomsen RW, Nielsen RB, Nørgaard M, Horsdal HT, Stürmer T, Larsen FB, Sørensen HT (2013) Lifestyle profile among statin users. Epidemiology 24: 619-620.

Zhao TT, Le Francois BG, Goss G, Ding K, Bradbury PA, Dimitroulakos J (2010) Lovastatin inhibits EGFR dimerization and AKT activation in squamous cell carcinoma cells: potential regulation by targeting rho proteins. Oncogene 29: 4682-4692.

Supplementary Information accompanies this paper on British Journal of Cancer website (http://www.nature.com/bjc) 